\title{
Transition Daze: A Qualitative Analysis of Transition Days in Blended Families
}

\author{
Charity Perry-Fraser, Rick Fraser \\ Department of Sociology, California State University, Los Angeles, USA \\ Email: cperry5@calstatela.edu, rfraser@calstatela.edu
}

Received 11 May 2016; accepted 12 July 2016; published 15 July 2016

Copyright (C) 2016 by authors and Scientific Research Publishing Inc.

This work is licensed under the Creative Commons Attribution International License (CC BY). http://creativecommons.org/licenses/by/4.0/

(c) (i) Open Access

\begin{abstract}
The current research enhances the understanding of transition day for researchers and clinicians who focus on marriage and family issues. A qualitative study involving 13 members (parents) of various stages of stepfamily development and demographics, is assessed. Interviews included questions for parents in a blended family and focused transitional day specific questions. By gaining a more in-depth understanding of transitional days in stepfamilies, immediate assistance may be provided to families who encounter difficulties during various stages of stepfamily/blended family formation. Useful approaches for current stepfamilies and future stepfamilies are discussed. Lastly, a new term is coined by the authors: "Transition Daze".
\end{abstract}

\section{Keywords}

Qualitative, Stepfamily, Blended Family, Transition, Transition Days

\section{Introduction}

The prevalence of stepfamily membership continues to grow. For example, a national report conducted by the Pew Research Center on adults in America (Parker, 2011) noted that 42\% (95.5 million) of adults have a steprelationship consisting of a stepparent, step or half sibling, or stepchild. Nationally, $13 \%$ of adults are stepparents (29 - 30 million), 15\% (16.5 million) of men are step-dads, and 12\% (14 million) of women are stepmoms. The purpose of this study was to gain greater understanding of transitional days in the development of stepfamilies by systematically evaluating the content of semi-structured interviews collected from family members. Transitional days occur when families are in the process of forming or altering a stepfamily or blended family. Cherlin (2010) concluded that serial transitions in and out of marriage/divorce/cohabitation are now typical of family life in the United States. Americans marry, divorce, and cohabit more often than any other Western society and they are likely to start and stop relationships more quickly. A comprehensive understanding of 
transitional days in stepfamilies is potentially beneficial to all families, those present and future. Children of blended families experience multiple changes in their environment. Moving households, adjusting to two households, addition or subtraction of siblings, and a change in school or social networks are but a few of the issues that children face. Multiple transitions in particular can have an effect on the psychological well-being children.

\section{Statement of the Problem}

Although there are over 1,000 empirical articles that focus on aspects of stepfamily dynamics, demographics and behavior, there is a paucity of research regarding the subjective processes associated with stepfamily formation (Browning \& Artelt, 2012; Claxton-Oldfield, 2008; Lagoni \& Cook, 1985; Leon \& Angst, 2005). Little interest has been paid to the familial experience during days of transition within a stepfamily (DeGreeff \& Burnett, 2009; Schrodt \& Braithwaite, 2011).

\subsection{Purpose of the Study}

The purpose of this study is to understand stepfamily development during transitional days and to foster a greater understanding of the issues that arise in the stepfamily during such transitions. The current study provides research results that are applicable to the field of marriage and family therapy and provides a foundation in which narratives of stepfamilies interviewed may be examined further to identify their experiences. Thirteen parents who were family members of a stepfamily or a blended family were interviewed. The experiences recorded on transition days within families were obtained by interviewing biological parents and stepparents of reconstituted families. The current study conveys a greater understanding of stepfamily processes on transitional days in blended families.

\subsection{Review of Literature}

Research suggests successful stepfamilies have realistic expectations about stepfamily dynamics and development. They have realistic expectations about the time necessary to establish roles and to determine their family's natural pattern of functioning (e.g. Hetherington \& Kelly, 2003; Visher et al., 2003). Discussion will be limited to theories that may be relevant for elucidating factors associated with successful and unsuccessful transitions.

\section{Theoretical Approaches to Stepfamily Transition Research}

Conflict Theory: Conflict theory may have particular relevance for explaining the balance between order and disorder in work and family structures (Ritzer, 1989). In conflict theory, the blended family goes through a process of trying to "fit" together two family systems. Naturally, conflicts arise that must be addressed for a family to achieve harmony. Adherents to this theory argue that conflict theory can explain how harmony in blended and stepfamilies can exist, despite the conflicts, inequitable distributions of power, and oppressive social conditions (Sprey, 1969).

Stage Theory: Modern stage theories have their basis in older stage theories that focused on development and grief (Pfeifer \& Blakemore, 2012). Papernow (1993) described how stepfamilies evolve, based on responses to individual and systemic changes of the entire family. Papernow described six stages of the stepfamily cycle: immersion, awareness, mobilization, action, contact and resolution. In the current study, a questionnaire was created with questions that mirror each one of these stages. For children of stepfamilies, feelings can be conflicting and complicated by social, emotional, and developmental matters (L'Abate, 1976, 1986). The current study also relies on the notion that stages may be present or not, and are not necessarily rigid and sequential; e.g., families may oscillate between the stages (McManus-Gay, 2002; Papernow, 1993). When applied to families, stage theory maintains that we cannot expect to know exactly how long each individual family member will remain in a specific stage. Empathy between members of a stepfamily is particularly important so that the family unit may continue to create a space in which a family may evolve to the final stages of stepfamily development, contact and resolution.

Complementary and overlapping concepts of transitions and family systems have been examined in other literature (Downes, 2009). Many children of divorced families exhibit maladaptive behaviors, often being uncooperative or worse, and are labeled as "pathological". Family theorists posit that unbalanced family systems may 
be the trigger of such behaviors. Furthermore, family systems theorists believe that understanding the sum of the parts and their connection to the whole system is integral to understanding the complexity of transitional days within stepfamilies.

\subsection{Methodology}

This study uses qualitative research methods to explore the content of transitional days for newly constituted families. Such methods have been effectively applied in similar research paradigms (see e.g. Burck, 2005; Coulehan, Friedlander, \& Heatherington, 1998; Couture \& Sutherland, 2004; Friedlander, Wildman, Heatherington, \& Skowron, 1994; Frosh, Burke, Strickland-Clark, \& Morgan, 1996; Gehart, Ratliff, \& Lyle, 2001; Helmeke \& Sprenkle, 2000; Kogan, 1998; Kogan \& Gale, 1997; Sprenkle \& Moon, 1996).

\subsection{Participant Selection}

The following selection criteria were used: a) The interviewee was a parent in a blended family or stepfamily, and b) The interviewee was open and willing to discuss their experiences about transitional days in stepfamilies.

Procedures: One-on-one semi-structured interviews were conducted. Each interview was treated as a unique event, i.e., each interview was considered individually in the analysis. Common themes were identified across the interviews.

The narratives were analyzed for: interpretation of reality, changes in the interviewee's perceptions of reality and unique aspects of the interview (Bamberg, 2012). While, analysis of the narratives required a reduction of the data, the narratives were carefully analyzed for information on transitional days in stepfamilies.

\subsection{Presentation of Results}

Thirteen participants were interviewed regarding transition day specific questions along with a demographic questionnaire pertaining to the participants current occupation and level of educational attainment (see Table 1).

Participant Characteristics: Table 1 summarizes the characteristics of each participant. These descriptions include the participant's age, relationship status, children type and custody arrangement.

\subsection{Data Analysis Findings}

Patterns, themes, and dimensions were extracted from the collected data by analysis of the interviews, coding of the data, and further analysis as themes and patterns emerged. The goal was to describe the participants'

\begin{tabular}{ccccc} 
Table 1. Demographic characteristics of the interviewees. & \\
\hline Participant & Age & Relationship status & Children type & Custody \\
\hline P1 & $30-39$ & Cohabitating & Both & $45 / 55$ \\
P2 & $50-59$ & Cohabitating & Biological & $50 / 50$ \\
P3 & $30-39$ & Married & Step & $70 / 30$ \\
P4 & $30-39$ & Cohabitating & Step & $80 / 20$ \\
P5 & $40-49$ & Married & Both & $70 / 30$ \\
P6 & $50-59$ & Married & Both & $50 / 50$ \\
P7 & $30-39$ & Married & $50 / 50$ \\
P8 & Married & Both & $95 / 5$ \\
P9 & $50-59$ & Married & Step & $50 / 50$ \\
P10 & $30-39$ & Both & $50 / 50$ \\
P11 & $40-49$ & Married & Both & $20 / 80$ \\
P12 & $60-69$ & Married & Both & $80 / 20$ \\
P13 & $50-59$ & Married & Both & $50 / 50$ \\
\hline
\end{tabular}


subjective experiences and views.

Coding: Transition Day as a theme was identified from the coding process. Transition Day was further classified into subthemes. The findings for the research questions are summarized below with brief quotes that exemplify the themes or subthemes.

\section{Overall Findings}

The primary theme of transition day and the subthemes related to this research question are summarized in this section. Table 2 shows the frequency with which the themes appeared across interviews.

Subthemes of Transition Day: The subthemes of transition day were: try to connect with kids, make comfortable, and gather belongings. In total, there were six subthemes for transition days.

Subtheme 1: Try to connect with kids. The primary subtheme for transition day was to try to connect with kids. Interviewees referenced trying to connect with kids on transition days. It was mentioned nine times in four interviews. Participant 4 shared:

"I think when they return I try to connect in a way just to let them know that I'm here, and I know that it is hard for them, and try and make the day maybe more fun. And just my talking to my stepdaughter and letting her know that I understand maybe some of the things that she is feeling."

Participant 5 described how her blended family of her biological children and her spouse's biological children connect, saying:

"And we sit down as a group and we try to keep that Friday reconnecting time. We purposely do not plan anything on those nights because the weekend, we have found, goes so much better when we don't."

Subtheme 2: Make comfortable. The second subtheme was to make the situation more comfortable. Interviewees referenced preparation for transition day by making sure that the house was ready for the kids to arrive. It was mentioned eight times in eight interviews. Participant 12 shared:

"We prepared for her to come by having a-a room ready for her room, a bed ready, and-and, uh, an idea of trying to, uh, trying to get an idea of what we wanted to do when she was here, activities, things like that to keep her occupied."

Participant 5 said, "The boys really thrive on routine, so I make sure that their room and the things that they like—or set up kind of the way that they like." Participant 6 said, "We just make sure there is food in the house and he's got plenty of stuff to eat. And it is his responsibility to keep his room clean."

Subtheme 3: Gather belongings. The third subtheme was to gather belongings. Interviewees referenced the process of gathering belongings on transition day. It was mentioned seven times in five interviews. Participant 5 said, "Their ability to plan for themselves is substantial. They have very, um, thinking of what they are going to need for dad's house and school and the coming days and plan for it.” Participant 3 shared:

"They just gather their stuff. I think it has become such a routine and we are consistent with our routine they just know. It's like, okay, today's Wednesday. Get your animals. Put them in here. Let's go. And that's it.”

Subtheme 4: Expect upset. The fourth subtheme was to expect upset. Interviewees referenced expecting children to be upset on the transition day. It was mentioned five times in four interviews. Participant 3 described the first day her children arrive from her ex-spouse's home, saying, "Usually that first day, Wednesday, is always a rough, a rough day. They're fighting with each other, they're acting out. They're just very sensitive.”

Table 2. Frequency of subthemes for research questions.

\begin{tabular}{ccc}
\hline Theme and subthemes & N mentioning & Exemplar quotes \\
\hline Transition day & 4 & 9 \\
Try to connect with kids & 8 & 8 \\
Make comfortable & 5 & 7 \\
Gather things they need & 4 & 5 \\
Expect kids to be upset & 3 & 5 \\
Prepare to spend time & 3 & 3 \\
Transition off schedule & & \\
\hline
\end{tabular}


Participant 4 shared:

"When they would go for the weekend... we prepared for them to be upset emotionally, maybe have tantrums, maybe be tired, hungry, just kind of out of sorts, out of their normal schedule, and just to have a little more patience on that day. Because that, you know, some kids are emotionally, not necessarily able to process all the stuff that they are feeling missing one parent and coming back to another.”

Subtheme 5: Prepare to spend time. The fifth subtheme was prepare to spend time. Interviewees referenced preparing to spend time with kids on their day of arrival. It was mentioned five times in three interviews. Participant 5 said, "They come on the weekends [so] we're making sure that things are kind done and taken care of so that we can really enjoy our time with them. So that takes some preparation during the week.” Participant 3 shared:

"My nanny comes on Wednesday and she cooks for us and kind of tidies up the house and does my grocery shopping. It allows me to spend more time with them when I bring them home on Wednesdays because I have not seen them for so many days.”

Subtheme 6: Transition off schedule. The sixth subtheme was transition off-schedule. Interviewees referenced parents not being on schedule for drop-off on transition days. It was mentioned three times in three interviews. Participant 10 said, “She had a lot of pull. Whatever she wanted she did. She didn't listen to agreements. She would do whatever. She would bring them late.” Participant 5 shared:

"The mom of my stepchildren would try to time the visits like right when the one of the children were not crying and then she would say he's not crying, I'm going to drop him off right now. And the whole schedule would get messed up."

Participant 11 recalled:

"There were a lot of ah, oh well she is not coming now. She does not want to or she's-we've got something else to do or whatever. That was probably the worst adjustment was that you would plan things and then have to- then get shut down a lot."

\subsection{Discussion of Findings}

The primary subthemes of the transition day theme were connecting with kids, making kids comfortable, gathering belongings for children (referenced below as physical needs), expectations, spending time together, and schedules.

Subtheme 1: Connecting with kids. The primary subtheme of the transition day theme referenced in interviewee's remarks was about connecting with their kids on days of transition. Interviewees described trying to connect with their children to let them know that the parent was there for them, in some cases even creating a day that included fun to help ease the transition. Another interviewee tried to connect with their stepchild by talking to them and acknowledging the difficulties of transitioning. Others made a point to connect on a specific day while still others stayed away from planning anything on transition days, finding that not planning worked better for their family.

Subtheme 2: Transition day and comfort. The second subtheme was about making their children feel comfortable. Interviewees prepared for the transition day by making sure that the house was ready for the kids to arrive. Interviewees shared that they prepared by having the child's room ready to go on the day of transition, pre-planned activities to keep children occupied. Other interviewees noted their children thrived on routine so remedies ranged from making sure their personal belongings were set up the way their children liked them to making sure that there was plenty of food in the house.

Subtheme 3: Transition day and gathering belongings. The third subtheme involved the gathering of belongings on transition day. Some interviewees enjoyed their children's ability to plan for themselves. Other interviewees shared that consistency with the routine prepared them and their children for the impending days of transition.

Subtheme 4: Transition day and expectations. The fourth subtheme of transition day was expectations. Expecting to be upset was referenced by interviewees who believed that their children would be upset on transition days. Interviewees described the first day as being rough and that their children acted out, fought and were emotional. Other interviewees remarked when their children were preparing to leave their homes, they would have tantrums, were unusually hungry, were tired or out of sorts. An interviewee remarked they had to have more patience on that day because their children were not be able to process all of their feelings regarding missing one 
parent and coming back to another.

Subtheme 5: Transition day and spending time together. The fifth subtheme was preparation to spend time together. Interviewees referenced preparing to spend time with their kids on the day of arrival. Interviewees shared that they got things done during the week so they could better enjoy time with their children. Another interviewee hired a nanny to run errands, cook and tidy up the home so the interviewee could spend more time with the children.

Subtheme 6: Transition day and schedules. The sixth subtheme was about transitions that were off-schedule or about parents not being on schedule for transition day drop-offs. It was referenced three times in three interviews. Interviewees shared that their ex-spouses did whatever they wanted to and did not follow agreements. Another interviewee remarked that their stepchild's mom would only drop the child off when she felt she was ready thus messing up their entire schedule. Other interviewees planned things for their children or stepchildren only to have the other parent pull out of the visit at the last minute.

\subsection{Conclusions}

This study was intended to explore and develop a fundamental understanding of transitional days in stepfamilies. A dominant theme elucidated from the analysis was transition day.

Conclusion:

It is important to consider the data provided by the thirteen family members at the conclusion of their interviews that provided greater understanding of change in homeostasis that the families experienced during transitional days. The families interviewed for the current study were parents in various stages of stepfamily/blended family formation. They provided valuable insight for individuals who are involved in a stepfamily/blended family environment. These individuals include clinicians, researchers and educators, who are invested in gaining a greater understanding of the different processes involved for children.

The participants of the current study had considerable diversity with respect to age, gender, marital status, ethnicity, parental status (bio-step), religion, educational attainment, occupational diversity, previous marital statuses and custody arrangements. Interviewees provided information about the other parent (remarriage) and children present in their homes and their ex-spouses homes. Additional information about cohabitation before marriage or the partnership with their current mate was also collected.

Family systems theory proposes that stable systems are created when the individuals that make up the system interact in such a way as to create systemic homeostasis. Instability occurs when in the process of transition; these systems are broken apart and reconstituted. By their very nature these processes of disconnect and reconstitution are fluid. The stress that results from this process can be either positive or negative. In the positive sense, successful reconstitution creates new opportunities such as role change, personal growth, and/or new alliances. On the negative side, the process of disconnecting may mean loss, emotional uncertainty, fragmentation, and family chaos. Transitional days present a challenge to the system due to the disconnection and reassembly processes that occur. Parents in this study acknowledged this difficulty was foremost in their minds and that it led to behaviors that allowed them to soften the impact during transitional times.

It was reassuring to discover that parents were not only responsible in creating regular transitions with their children but were also aware of the importance that transitional days can have on their children's development. Parents employed a variety of behavioral, emotional and rational responses to their children's needs and concerns during such times. Parents made an effort to connect with their children during days of transition. The approaches used to connect were multi-dimensional. Some designated a day to reconnect as a group, others reconnected with their children by taking the time to discuss what their children were feeling. Still others allowed emotional space for children during the day of transition. All of these observations indicated that parents are aware of their children's special needs during days of transition.

A second subtheme of connecting with children is how parents sought to make their children comfortable. While the transitional day can be one of disconnections and chaos, there is a fundamental goal to make the transition smoother and simpler for both parents and children. In the current study, parents could choose to focus on themselves solely and make themselves more comfortable. Alternatively, parents could have been aware of their children's discomfort and could have attended to their children's needs. This may have occurred unconsciously, whereby parents focus on their own disconnect and striving to manage their own feelings of fragility and/or authority. In addition, it could have occurred because parents may have been altruistic by being aware of their 
child's needs. Presumably, these are not mutually exclusive efforts; these efforts can simultaneously occur as a family system experiences feelings of disconnectedness and fragility. The act of providing comfort to children during transition days can also provide comfort to the parent, which would allow them to externally address their own internal needs for stability and security.

Another overt way in which parents address the transition day is to make sure that children have the things they need to take with them to the other household or have brought everything they need from the other household. One of the largest battles between households that can affect children is the management of material resources. These include not only the tangible items of clothing, project materials, school materials and personal items, but also the intangible tasks and responsibilities that need to be addressed. School materials and assignments reflect the overt material that is passed back and forth, but they also act as a metaphor for the differing concerns the parents may have between the two households. Parents cannot assume that the other household will attribute the same value to these material items. They must therefore be vigilant about making certain that such items are respected in a way that is congruent with their home. Parents are often acutely aware that items that leave their home may be subjected to the interpretation of the ex-spouse and therefore have an uncertain meaning. Parents that try to control how an item is used or manipulated may wind up communicating one thing to the child and another to the ex-spouse. While this may be inadvertent, it still suggests that parents who are involved in days of transition have to bear in mind the opinions, attitudes, and behaviors of the ex-spouse when transferring materials back and forth and when using their children as messengers. The amount of conflict surrounding the movement of items back and forth from one household to another is often indicative of the significance of the item itself.

Parents adapt to the stress of transitional days by modifying their expectations of their children and of the emotional homeostasis of the day. The parents in the current study have come to "expect upset;" they have changed their expectations of the emotional responses that are likely to be exhibited by a child and by themselves. This is important because parents need to be consciously aware that there may be conflict and chaos which needs an additional amount of flexibility and tolerance on their part. There may be certain days during the week in which a heightened sense of anxiety, fear, or frustration must be addressed by parents on a regular basis. Even the excitement of reunification creates stress, which individuals may or may not be cognizant of, but is embedded throughout the family system. In the most positive view, these changing expectations can provide families with a more conscious "here and now" emotional exchange. In the least favorable perspective, these changing expectations can be exhausting, inconsistent and therefore debilitating.

The final subtheme of the current study was transition days in which the transition was not planned or was inconsistent in execution. These transitional times created conflict between family households, as well as, emotional frustration between parents and children. Several parents acknowledged that transitional days were not consistent by time or date. While the current study does not go into the reasons why the changes were made, it is important to note that not all transitional days were regular. Much of this depends on the relationships between the parents and their ability to negotiate a formalized agreement.

There are both positive and negative aspects of these inconsistent transitions. Some divorced parents feel close enough to each other that they allow children to make their own decisions to move between the two households. On the other hand, some parents will try to maintain control over the relationship by controlling the child's availability to the other parent. This may occur for a variety of emotional, cognitive, or environmental reasons. Children involved in this second category may perceive that life is capricious because there are inconsistencies in the way that a parent manages transitions. In stepfamily or blended families dysfunction tends to occur on a regular basis so the family system learns to be more efficient, even in the face of the circumstances noted above.

The current researchers have coined the term, "Transition Daze" to exemplify the confusion, both internally and externally that a child experiences during this time. The authors believe that this state, while being unavoidable is not necessarily advantageous or detrimental. In fact the authors feel that how families mediated this transition had a lot to do with how the child perceived the change and subsequent self-identification as being positive or negative. An obvious example of this is the parents who greet each other and share anecdotal information about the child in a positive and relaxed manner during the transition time itself. Dropping the child off at the door or refusing to leave a car during this time is interpreted by the child in a much more negative manner. Hence we see this time as an opportunity for parents to facilitate the positive growth and development of their children during a tumultuous time. 
It is important to recognize that, as alluded to above, this "transitional daze" is unavoidable regardless of the good intentions of the parents. Homeostatic systems, like families, will respond to change in measurable and consistent ways. Identifying the cognitive and emotional impact of the change is as important as recognizing the physical change that is overtly taking place. Families try to minimize the discomfort in a variety of ways but often fail to realize that the very means by which they integrate or try to reconnect creates the very confusion they are trying to avoid. It is inevitable. Identifying the internal factors that influence particular children and addressing them in a concrete, consistent manner is as important as having a safe home environment that welcomes them.

Finally, "transitional daze" is not meant merely as a one-time event. The authors believe that successful transition can be accomplished in a short time period when parents are supportive and available. In contrast the transitional chaos can be continued for days, weeks and even years for families that are not supportive and maintain a high amount of hostility toward each other. This is particularly obvious in "high conflict" divorce when parents may maintain a hostile enmeshment through the court battle. In this case children do not transition between healthy systems but rather are caught in limbo and integrate the confusion and hostility of the environment into their self identity rather than expand themselves with new experiences. Identity is therefore slower to develop with all the potential consequences that parents are most concerned about. This research is meant to be a preliminary investigation in to how parents respond to this event in the hopes that more concrete and empirical responses to this time may be realized.

\subsection{Limitations of Current Study}

Qualitative research can have multiple interpretations, which are dependent the researcher's biases and experiences. Qualitative interviews are subjective, leading to the second limitation, generalizability. Arguably the subjective nature of the current study minimizes generalizability to a larger population. There was considerable variability in the demographics and backgrounds of the interviewee's. The interpretation of the questions posed in this study may have differed among participants because of their differing cultural backgrounds, age, and education attainment.

\subsection{Future Research on Transition Days in Stepfamilies or Blended Families}

Future research should continue a qualitative focus on family success and competence in the family experience. Family meaning subjectivity would assist in clarification of how stepfamily processes unfold thereby giving meaning to the content of a narrative being told. Future research should involve the narratives of children to bring about a greater understanding of their perceptions of the processes of stepfamily formation. To gain a greater perspective of transitional days in stepfamilies or blended families, other geographical regions, rural environments, and different economic environments should be researched. Longitudinal studies would provide a long-term perspective of children's adaptation with such variables as importance of the spouse's relationships or the importance of structured agreements. Other areas of importance may include the differences in outcomes for children that move into blended families with other children versus children that cohabit with a step-parent who does not have children. The number of transitional days per week should be researched to identify the importance of multiple transitional times during the week.

\section{References}

Bamberg, M. (2012). Narrative Analysis. In H. Cooper (Ed.), APA Handbook of Research Methods in Psychology (3 Volumes). Washington DC: APA Press. http://dx.doi.org/10.1037/13620-006

Browning, S., \& Artelt, E. (2012). Stepfamily Therapy: The 10 Steps. American Psychological Association. http://dx.doi.org/10.1037/13089-003

Burck, C. (2005). Comparing Qualitative Research Methodologies for Systemic Research: The Use of Grounded Theory, Discourse Analysis and Narrative Analysis. Journal of Family Therapy, 27, 237-262.

http://dx.doi.org/10.1111/j.1467-6427.2005.00314.x

Cherlin, A. J. (2010). The Marriage-Go-Round: The State of Marriage and the Family in America Today. Random House Digital, Inc.

Downes, R. D. K. R. (2009). Transitions and Family Systems.

Friedlander, M. L., Wildman, J., Heatherington, L., \& Skowron, E. A. (1994). What We Do and Don’t Know about the 
Process of Family Therapy. Journal of Family Psychology, 8, 390. http://dx.doi.org/10.1037/0893-3200.8.4.390

Frosh, S., Burck, C., Strickland-Clark, L., \& Morgan, K. (1996). Engaging with Change: A Process Study of Family Therapy. Journal of Family Therapy, 18, 141-161. http://dx.doi.org/10.1111/j.1467-6427.1996.tb00041.x

Gehart, D. R., Ratliff, D. A., \& Lyle, R. R. (2001). Qualitative Research in Family Therapy: A Substantive and Methodological Review. Journal of Marital and Family Therapy, 27, 261-274. http://dx.doi.org/10.1111/j.1752-0606.2001.tb01162.x

Helmeke, K. B., \& Sprenkle, D. H. (2000). Clients' Perceptions of Pivotal Moments in Couple Therapy: A Qualitative Study of Change in Therapy. Journal of Marital and Family Therapy, 26, 469-483. http://dx.doi.org/10.1111/j.1752-0606.2000.tb00317.x

Hetherington, E. M., \& Kelly, J. (2003). For Better or for Worse: Divorce Reconsidered. New York: W. W. Norton \& Company.

Kogan, S. M. (1998). The Politics of Making Meaning: Discourse Analysis of “Postmodern” Interview. Journal of Family Therapy, 20, 229-251. http://dx.doi.org/10.1111/1467-6427.00085

Kogan, S. M., \& Gale, J. E. (1997). Decentering Therapy: Textual Analysis of a Narrative Therapy Session. Family Process, 36, 101-126. http://dx.doi.org/10.1111/j.1545-5300.1997.00101.x

L’Abate, L. (1976). Understanding and Helping the Individual in the Family. New York: Grune \& Stratton.

L’Abate, L. (1986). Systematic Family Therapy. New York: Brunner/Mazel.

Lagoni, L. S., \& Cook, A. S. (1985). Stepfamilies: A Content Analysis of the Popular Literature, 1961-1982. Family Relations, 34, 521-525. http://dx.doi.org/10.2307/584013

Leon, K., \& Angst, E. (2005). Portrayals of Stepfamilies in Film: Using Media Images in Remarriage Education. Family Relations, 54, 3-23. http://dx.doi.org/10.1111/j.0197-6664.2005.00002.x

McManus-Gay, A. (2002). From Discord to Harmony: Creating a Stepfamily Paradigm. Proquest Information and Learning. UMI.

Papernow, P. L. (1993). Becoming a Stepfamily: Patterns of Development in Remarried Families. San Francisco, CA: Jossey-Bass.

Parker, K. (2011). A Portrait of Stepfamilies. Pew Social Trends. http://pewsocialtrends.org/2011/01/13/a-portrait-of-stepfamilies/

Pfeifer, J. H., \& Blakemore, S. J. (2012). Adolescent Social Cognitive and Affective Neuroscience: Past, Present, and Future. Social Cognitive and Affective Neuroscience, 7, 1-10. http://dx.doi.org/10.1093/scan/nsr099

Ritzer, G. (1989). Sociology of Work: A Metatheoretical Analysis. Social Forces, 67, 593-604. http://dx.doi.org/10.1093/sf/67.3.593

Schrodt, P., \& Braithwaite, D. O. (2011). Coparental Communication, Relational Satisfaction, and Mental Health in Stepfamilies. Journal of Personal Relationships, 18, 352-369.

Sprey, J. (1969). The Family as a System in Conflict. Journal of Marriage and Family, 31, 699-706. http://dx.doi.org/10.2307/349311

Visher, E. B., Visher, J. S., \& Pasley, K. (2003). Remarriage Families and Stepparenting. Normal family Processes: Growing Diversity and Complexity, 3, 153-175. 


\section{Submit or recommend next manuscript to SCIRP and we will provide best service for you:}

Accepting pre-submission inquiries through Email, Facebook, LinkedIn, Twitter, etc.

A wide selection of journals (inclusive of 9 subjects, more than 200 journals)

Providing 24-hour high-quality service

User-friendly online submission system

Fair and swift peer-review system

Efficient typesetting and proofreading procedure

Display of the result of downloads and visits, as well as the number of cited articles

Maximum dissemination of your research work

Submit your manuscript at: http://papersubmission.scirp.org/ 